\title{
The prevalence and the course of neuropsychiatric symptoms in patients with dementia
}

\author{
Sverre Bergh ${ }^{1,2}$ and Geir Selbæk ${ }^{1,3}$ \\ 1) Innlandet Hospital Trust, Centre for Old Age Psychiatric Research \\ 2) The Norwegian Centre for Dementia Research \\ 3) Akershus University Hospital \\ Correspondence: Sverre Bergh, Norway, Innlandet Hospital Trust, Centre for Old Age Psychiatric Research, Pb 68, 2312 Ottestad \\ E-mail: Sverre.bergh@sykehuset-innlandet.noＴelephone: +4745679393
}

\begin{abstract}
Dementia is prevalent in Norway and other countries and is hallmarked by a decline in memory and other cognitive abilities. In addition to cognitive decline, the vast majority of patients with dementia experience neuropsychiatric symptoms (NPS) such as depression, agitation, psychosis, apathy, or irritability. In this review, we describe the prevalence and the course of NPS in patients with dementia, referring to results of population-based studies, studies of outpatients, and studies of patients in long-term care. For a better comparison of the included studies and for clarification, we have included studies that have assessed NPS with the Neuropsychiatric Inventory (NPI). Overall, we found a high prevalence rate of NPS. At least one NPS (NPI $>0$ ) was present in $56 \%$ to $98 \%$ of the patients and $62 \%$ to $84 \%$ of the patients had at least one clinically significant NPS (NPI > 3). The NPS with the highest prevalence rate were apathy, irritability, agitation, depression and anxiety; while delusion, hallucination, disinhibition, aberrant motor behavior and euphoria were the least frequent NPS.
\end{abstract}

\section{INTRODUCTION}

Dementia is a syndrome consisting of several symptoms and hallmarked by a decline in cognition that leads to functional impairment. In order to diagnose dementia by the ICD-10 criteria, a decline in memory, a decline in other cognitive abilities, a decline in emotional control or motivation, or a change in social behaviour should be present. The patient's awareness should be preserved, and the symptoms should be present for more than six months. Dementia is progressive and can be caused by several different diseases, such as Alzheimer's disease, Lewy Body dementia, Parkinson's disease, frontotemporal dementia, cerebrovascular diseases, and dementia due to excessive alcohol use. The impact of dementia on quality of life, on caregiver burden, and on the use of resources is substantial $(1,2)$.

The hallmark of dementia is cognitive decline, but accompanying neuropsychiatric symptoms (NPS) of dementia, such as apathy, depression, agitation and delusion, are prevalent. NPS are often more devastating and create more discomfort for patients and their caregivers than do the cognitive deficits, and studies have shown an inverse relationship between NPS, especially depression, and quality of life $(3,4)$. NPS are often treated with psychotropic drugs, in spite of limited evidence for efficacy and a considerable risk of adverse events (5).

In this article, we will refer to studies on the prevalence and the course of NPS in patients with dementia. We will include population-based studies, studies describing NPS in outpatients, and studies of patients living in long-term care. To be able to compare prevalence rates of NPS across studies, we have focused on studies assessing NPS with the 10 -item version of the Neuropsychiatric Inventory (NPI-10). We present prevalence rates of individual neuropsychiatric symptoms according to four sub-syndromes; agitation, affective symptoms, psychosis, and apathy.

\section{METHOD}

\section{Search strategy}

We have searched the electronic databases of MEDLINE from inception to June 2011. We used the following medical subject headings (MeSH-terms) and free-text words to identify articles on the prevalence and the course of neuropsychiatric symptoms in population-based studies, studies of outpatients, and patients in long-term care: "dementia" combined with "neuropsychiatric inventory" or "NPI" combined with "neuropsychiatric symptoms" or "behavioral and psychological symptoms of dementia" combined with "prevalence" or "course" combined with "populationbased studies" or "outpatients" or "nursing homes" or "long-term care". We included only articles in English. In total 108 citations was retrieved, and the abstracts were reviewed by the two authors. We also searched the reference lists of the retrieved articles for other relevant articles. The search resulted in four population based studies, 10 studies including out-patients and five studies including nursing home patients that are presented in this paper.

\section{Assessment scales for NPS}

Due to the cognitive decline in patients with dementia, loss of insight, and language and communication impairments, most of the patients, particularly at severe 
Table 1. Prevalence rates (\%) of neuropsychiatric symptoms in studies with population based samples assessed by the neuropsychiatric inventory.

\begin{tabular}{|c|c|c|c|c|c|}
\hline & $\begin{array}{c}\text { Tatsch, } 2006 \\
n=60\end{array}$ & $\begin{array}{c}\text { Ikeda, } 2004 \\
n=60\end{array}$ & \multicolumn{2}{|c|}{$\begin{array}{c}\text { Lyketsos, } 2002 \\
n=362\end{array}$} & $\begin{array}{c}\text { Lyketsos, } 2000 \\
n=329\end{array}$ \\
\hline Age, mean (SD) & $80.1(8.9)$ & $81.8(7.3)$ & \multicolumn{2}{|c|}{$77.0(5.0)$} & $84.2(7.0)$ \\
\hline MMSE score, mean (SD) & $15.5(4.9)$ & $16.4(6.8)$ & & & \\
\hline Symptoms & Alzheimer's disease ${ }^{1}$ & Dementia $^{2}$ & \multicolumn{2}{|c|}{ Dementia $^{1}$} & Dementia $^{1}$ \\
\hline Delusion & 12 & 27 & 18 & 11 & 19 \\
\hline Hallucination & 8 & 15 & 11 & 5 & 14 \\
\hline Agitation/aggression & 20 & 35 & 30 & 15 & 24 \\
\hline Depression & 38 & 22 & 32 & 16 & 24 \\
\hline Anxiety & 25 & 23 & 22 & 10 & 17 \\
\hline Euphoria & 5 & 8 & 3 & 1 & 1 \\
\hline Apathy & 53 & 57 & 36 & 27 & 27 \\
\hline Disinhibition & 17 & 8 & 13 & 7 & 9 \\
\hline Irritability & 23 & 31 & 27 & 12 & 20 \\
\hline Abberant motor behaviour & 10 & 32 & 16 & 12 & 14 \\
\hline Night time behaviour & 28 & & 27 & 20 & \\
\hline Eating change & 23 & & 20 & 16 & \\
\hline \multirow[t]{2}{*}{ At least one CS-NPS* } & 78 & 88 & 75 & 62 & 56 \\
\hline & $\mathrm{NPI}>0$ & $\mathrm{NPI}>0$ & $\mathrm{NPI}>0$ & $\mathrm{NPI}>3$ & $\mathrm{NPI}>0$ \\
\hline
\end{tabular}

stages of the disease are unable to rate their own symptoms. Hence, several assessment scales for NPS are based on observations of the patients by caregivers or relatives. The Neuropsychiatric Inventory (NPI) is a well-known global assessment scale widely used in research and clinical practice (6). The NPI originally consisted of 10 items (NPI-10): delusions, hallucinations, depression/dysphoria, anxiety, agitation/aggression, euphoria, disinhibition, irritability/lability, apathy and aberrant motor activity. Later, two neurovegetative items were added to the NPI (NPI-12): sleep and nighttime behaviour disorders, and appetite and eating disorders (7). Individual symptoms are rated as present or not during the last four weeks; subsequently, the frequency (1-4) and the severity (1-3) of the symptoms are rated. The frequency score and the severity score are multiplied into a sub-score ( 0 to 12 points, with the higher score indicating more severe symptoms), and the 12 sub-scores are added (min $0, \max 144$ points). Sub-scores above 3 on an individual item are regarded as clinically significant symptoms (8).

Based on factor analyses of the NPI, four clusters have been identified; agitation (agitation/aggression, disinhibition, and irritability), affective symptoms (depression and anxiety), psychosis (delusion and hallucination), and apathy $(9,10)$. In patients with Parkinson's disease dementia (PDD) four clusters have been identified (11); mood (depression, anxiety and apathy), psychosis (delusions and hallucinations), agitation (agitation) and apathy (apathy). In studies with longitudinal design, authors have described persistence and resolution of NPS. "Persistence" is defined as the ratio of patients with Clinically Significant NPS (CS-NPS) at follow-up to patients with CS-NPS at the previous assessment, and "resolution" is the ratio of patients without CS-NPS at follow-up to the patients with CSNPS at the previous assessment.

\section{RESUlTS}

\section{NPS in persons with dementia, population-based studies}

We identified four cross-sectional studies reporting prevalence rates for NPS assessed by the NPI (12-15), which are summarized in table 1 . The studies by Tatsch et al. included patients with Alzheimer's disease ( $\mathrm{n}=$ $60)$, while Lyketsos et al. (2000) $(n=329)$, Lyketsos et al. $(2002)(n=362)$, and Ikeda et al. $(n=60)$ included patients with dementia independent of etiology. All studies presented prevalence rates for NPS, defined as an individual NPI score $>0$, while the study by Lyketsos et al. from 2002 also describes the prevalence of a clinically significant NPS (NPI > 3). To be able to compare the results between studies, we will refer to the prevalence rates for NPS defined as an NPI score $>0$. The prevalence rates of at least one NPS ranged from $56 \%$ to $88 \%,(12-15)$. Most of the studies reported an increase in prevalence rates as the dementia becomes more severe (14).

\section{Psychosis}

Prevalence: The prevalence rates for symptoms of psychosis differed among the four studies, and ranges of prevalence rates were $12 \%$ to $27 \%$ (median $18.5 \%$ ) for delusion and $8 \%$ to $15 \%$ (median $12.5 \%$ ) for hallucination.

Course: Only one population-based study has investigated the course of NPS in patients with dementia. In 
Table 2. Prevalence rates (\%) of neuropsychiatric symptoms in clinical out-patients with dementia, assessed by the neuropsychiatric inventory.

\begin{tabular}{|c|c|c|c|c|c|c|c|c|c|c|}
\hline & $\begin{array}{c}\text { Garcia- } \\
\text { Alberca, } 2011 \\
n=125\end{array}$ & $\begin{array}{l}\text { Aalten, } \\
2007 \\
\mathrm{n}=2354\end{array}$ & $\begin{array}{c}\text { Toyota, } \\
2007 \\
n=261\end{array}$ & $\begin{array}{l}\text { Peters, } \\
2006 \\
n=576\end{array}$ & $\begin{array}{l}\text { Senanarong, } \\
\begin{array}{l}2005 \\
n=73\end{array}\end{array}$ & $\begin{array}{l}\text { Piccinini, } \\
\begin{array}{c}2005 \\
\mathrm{n}=50\end{array}\end{array}$ & $\begin{array}{c}\text { Fuh, } 2005 \\
n=320\end{array}$ & $\begin{array}{c}\text { Aalten, } \\
2003 \\
n=199\end{array}$ & $\begin{array}{c}\text { Benoit, } \\
2003 \\
n=499\end{array}$ & $\begin{array}{l}\text { Mega, } \\
1996 \\
n=50\end{array}$ \\
\hline Age, mean (SD) & $76.4(6.1)$ & $76.7(7.8)$ & $78.5(5.1)$ & $73.0(8.5)$ & $70.3(8.1)$ & $69.3(7.5)$ & $75.2(7.2)$ & $76.4(8.0)$ & $77.5(7.1)$ & $75.0(6.6)$ \\
\hline MMSE score, mean (SD) & $14.5(4.8)$ & $17.8(5.9)$ & $19.0(6.0)$ & $20.7(5.6)$ & $18.4(6.6)$ & $16.8(5.6)$ & $17.1(6.8)$ & $18.1(4.7)$ & $19.7(4.3)$ & $16.2(7.5)$ \\
\hline Symptoms & $\mathrm{AD}^{1}$ & $\mathrm{AD}^{4}$ & $\mathrm{AD}^{1}$ & Dementia $^{2}$ & $\mathrm{AD}^{1}$ & $\mathrm{AD}^{1}$ & $\mathrm{AD}^{1}$ & Dementia $^{3}$ & $\mathrm{AD}^{1}$ & $\mathrm{AD}^{1}$ \\
\hline Delusion & 38 & 19 & 51 & 26 & 27 & 30 & 31 & 35 & 18 & 22 \\
\hline Hallucination & 20 & 9 & 23 & 13 & 18 & 12 & 24 & 13 & 7 & 10 \\
\hline Agitation/aggression & 55 & 31 & 45 & 36 & 36 & 32 & 39 & 29 & 39 & 60 \\
\hline Depression & 60 & 37 & 39 & 49 & 30 & 68 & 47 & 57 & 40 & 38 \\
\hline Anxiety & 54 & 37 & 39 & 36 & 43 & 54 & 37 & 39 & 45 & 48 \\
\hline Euphoria & 4 & 5 & 7 & 9 & 7 & 24 & 8 & 7 & 7 & 8 \\
\hline Apathy & 74 & 55 & 64 & 59 & 45 & 74 & 42 & 59 & 56 & 72 \\
\hline Disinhibition & 30 & 10 & 17 & 27 & 30 & 24 & 21 & 13 & 12 & 36 \\
\hline Irritability & 66 & 32 & 25 & 43 & 48 & 32 & 42 & 40 & 37 & 42 \\
\hline Ab. motor behaviour & 47 & 28 & 44 & 36 & 43 & 46 & 31 & 35 & 22 & 38 \\
\hline Night time behaviour & 36 & 20 & & 26 & 38 & & 42 & 18 & & \\
\hline Eating change & 28 & 22 & & 32 & 27 & & 36 & 25 & & \\
\hline \multirow[t]{2}{*}{ At least one CS-NPS* } & 98 & & & 89 & & & & 92 & 88 & 88 \\
\hline & $\mathrm{NPI}>0$ & $\mathrm{NPI}>3$ & $\mathrm{NPI}>0$ & $\mathrm{NPI}>0$ & $\mathrm{NPI}>0$ & $\mathrm{NPI}>0$ & $\mathrm{NPI}>0$ & $\mathrm{NPI}>0$ & $\mathrm{NPI}>3$ & $\mathrm{NPI}>0$ \\
\hline $\begin{array}{l}{ }^{1} \text { NINCDS-ADRDA } \\
{ }^{2} \text { DSM-III-R } \\
{ }^{3} \text { DSM-IV } \\
{ }^{4} \text { Clinical dementia diagno }\end{array}$ & & & & & & & & & & \\
\hline
\end{tabular}

the Cache County study by Lyketsos et al., the patients were assessed four times over five years (16). Results are presented as prevalence rates for the remaining patients in the cohort at each assessment, showing an increasing prevalence rate for both delusion $(18 \%$ to $38 \%)$ and hallucination (10\% to $24 \%)(16)$.

Affective symptoms

Prevalence: Prevalence rates for depression ranged from $22 \%$ to $38 \%$ (median $28 \%$ ). Prevalence rates for anxiety ranged from $17 \%$ to $25 \%$ (median $22.5 \%$ ).

Course: In the Cache County study, there was an increase in the prevalence rates of affective symptoms in the remaining patients during the five-year follow-up period: anxiety (14\% to $32 \%)$ and depression $(29 \%$ to $47 \%)(16)$.

\section{Agitation}

Prevalence: The individual symptom in the agitation sub-syndrome with the highest prevalence rate was agitation/aggression (range $20 \%$ to $35 \%$; median $27 \%$ ), followed by irritability (range $20 \%$ to $27 \%$; median $25 \%$ ), aberrant motor behavior (range $10 \%$ to $32 \%$; median $15 \%$ ) and disinhibition (range $8 \%$ to $17 \%$; median $15 \%$ ).

Course: In the Cache County study, the prevalence rates for the agitation sub-syndrome were fluctuating, but did not show an increase over the five-year followup; irritability fluctuated between $17 \%$ and $27 \%$ and disinhibition between $2 \%$ and $15 \%$ (16).

\section{Apathy}

Prevalence: The prevalence rates of apathy in the five samples ranged from $27 \%$ to $57 \%$ (median $44.5 \%$ ).
Course: There was an increase in the prevalence rate of apathy in the Cache County study from 20\% at baseline to $51 \%$ after 5 years (16).

\section{NPS in persons with dementia attending outpatient clinics}

Results from studies assessing the prevalence rates of NPS in outpatient samples applying the NPI are summarized in table $2(9,17-25)$. Four studies $(9,17,23,24)$ presented the proportion of patients who experienced at least one NPI symptom ( $>0)$, which ranged from $88 \%$ to $98 \%$. Correspondingly, Benoit et al. found that $88 \%$ of the patients experienced at least one clinically significant NPI symptom (>3) (25). The study of Aalten et al., in which one of the inclusion criteria was having at least one clinically significant $(>3)$ NPI symptom, pooled several datasets, and some of the participants in other studies noted in the table may have been included in this study (18). Toyota et al. compared patients with early-onset dementia to patients with late-onset dementia and found that delusions, hallucinations, agitation/aggression, disinhibition, and aberrant motor behavior were more common in lateonset dementia (19). Longitudinal studies indicate that virtually all persons with dementia experienced NPS during the follow-up. One French study demonstrated that the prevalence of NPS overall increased over a four-year follow-up (26). Longitudinal studies using assessment scales other than the NPI demonstrate heterogeneity in the course of symptoms and that NPS may arise at any stage of dementia. However, agitation seems to be the most persistent symptom and shows an increasing severity with disease progression in a majo- 
rity of the studies, whereas the persistence of psychosis and depression shows greater variability (27-30). It should be noted that apathy was investigated rarely in these studies.

\section{Psychosis}

Prevalence: The prevalence rates for symptoms of psychosis differed among the eight studies (NPI $>0$ ) and ranged between $22 \%$ and $51 \%$ (median $30.5 \%$ ) for delusion and $10 \%$ and $24 \%$ (median $15.5 \%$ ) for hallucination. Aalten (2007) and Benoit (2003) found lower prevalence applying NPI $>3$ as a threshold value. A higher prevalence of both delusions and hallucinations was associated with increasing severity of dementia (22,23).

Course: Studies applying the NPI have reported minor changes in psychosis during up to two-year follow-ups (31). However, a French study reported decreased severity of delusions (32). A later French study, where 151 patients were followed for four years, showed that the prevalence of hallucinations, but not delusions, increased over the follow-up period (26).

\section{Affective symptoms}

Prevalence: For the affective symptoms of depression and anxiety, the prevalence rates (NPI $>0$ ) ranged between $30 \%$ and $68 \%$ (median $48 \%$ ) and $36 \%$ and $54 \%$ (median 41\%), respectively. In the studies applying NPI $>3$ as a threshold value Aalten (2007) found that prevalence rates of $37 \%$ for both depression and anxiety, whereas Benoit (2003) found that $40 \%$ experienced depression, whereas $37 \%$ had anxiety symptoms. Mega et al. found that increased severity of depression and anxiety was associated with increasing dementia severity (24).

Course: Aalten et al. found a decrease in severity of depressive symptoms over a two-year follow-up (31).

\section{Agitation}

Prevalence: The prevalence rates of the individual symptoms in the agitation sub-syndrome (NPI $>0$ ), presented in decreasing order, were irritability (range $25 \%$ to $66 \%$; median $42 \%$ ), aberrant motor behavior (range $31 \%$ to $47 \%$; median $40.5 \%$ ), agitation/aggression (range $29 \%$ to $60 \%$; median $37.5 \%$ ), and disinhibition (range $13 \%$ to $36 \%$; median $25.5 \%$ ). Using NPI $>3$ as a threshold value Aalten (2007) and Benoit (2003) found that the figures of irritability and agitation/aggression were inside the range of the other studies, whereas the figures for aberrant motor behavior and disinhibition were lower than the range in the other studies. More severe agitation/aggression, disinhibition, and aberrant motor behavior were associated with increasing severity of the dementia (20,22-24).

Course: Agitation symptoms were among the most persistent and aberrant motor behavior, and disinhibition increased during follow-up $(31,32)$. Gonfrier et al. reported that the prevalence of aberrant motor activity, agitation/aggression, and disinhibition increased over a four-year follow-up (26).

\section{Apathy}

Prevalence: Apathy showed the highest prevalence in six of the eight studies (NPI $>0$ ), ranging from $42 \%$ to $74 \%$ with a median of $61.5 \%$. The studies that failed to find apathy as the most common symptom were conducted in Asia. Correspondingly, apathy was the most common symptom in the two studies using NPI $>3$ as a threshold value. The severity of apathy was associated with increasing severity of dementia $(20,23,24)$.

Course: Apathy was among the most persistent symptoms and showed increasing severity during the follow-up $(26,31,32)$.

\section{NPS in persons with dementia living in long-term care}

The prevalence rates of clinically significant NPS, defined as a score $>3$ on an individual NPI item, for patients in long-term care settings have been presented in several studies in recent years (see table 3) (33-37). The proportion of patients with at least one NPI item score $>3$, was $68 \%$ to $84 \%$ (median $72 \%$ ), depending on the severity of the dementia and the etiologic diagnosis. A large study in Norwegian nursing homes reported an overall prevalence of NPS of $55 \%$ in mild dementia $(\mathrm{CDR}=1), 70 \%$ in moderate dementia (CDR $=2)$ and $84 \%$ in severe dementia $(C D R=3)(34)$. Several studies report the course of NPS in patients in nursing homes, but the studies show heterogeneity in the course of the symptoms as well as the symptoms showed intermittent courses. Psychotic symptoms remained constant over time, while the prevalence rates of aberrant motor behavior, depression, anxiety, and euphoria declined and apathy, agitation/aggression, irritability, and disinhibition increased over time (38).

\section{Psychosis}

Prevalence: The prevalence rates of delusion vary across the different studies, with a range of $9 \%$ to $26 \%$ (median 16\%). Hallucination was approximately half as frequent as delusion, with prevalence rates ranging between $3 \%$ and $14 \%$, and a median of $8 \%$.

Course: The course of the psychotic symptoms over one year was described in two studies $(39,40)$. In one of the studies, a significant increase in the prevalence rates of delusion and hallucination was found over the one-year follow-up (39), while there was no change in psychotic symptoms in the other study (40). Wetzels et al. described a resolution rate over a six-month period of $50 \%$ for hallucination and $64 \%$ to $88 \%$ for delusion, indicating that psychotic symptoms have a fluctuating course (35). The same pattern was described by Bergh et al., who found a resolution rate close to $40 \%$ for delusion and hallucination over a four-month period (36).

\section{Affective symptoms}

Prevalence: Prevalence rates of affective symptoms were comparable across the seven studies: depression $8 \%$ to $22 \%$ (median $20 \%$ ) and anxiety $17 \%$ to $26 \%$ (median 22\%). 
Table 3. Prevalence rates (\%) of clinically significant neuropsychiatric symptoms in nursing home patients assessed by the neuropsychiatric inventory.

\begin{tabular}{|c|c|c|c|c|c|}
\hline & $\begin{array}{c}\text { Bergh, } 2011 \\
n=169\end{array}$ & $\begin{array}{c}\text { Wetzels, } 2010 \\
n=290\end{array}$ & $\begin{array}{c}\text { Zuidema, } 2007 \\
\text { n=1322 }\end{array}$ & $\begin{array}{c}\text { Selbaek, } 2007 \\
n=993\end{array}$ & $\begin{array}{c}\text { Margallo-Lana, } 2001 \\
n=137\end{array}$ \\
\hline Age, mean (SD) & $84.9(6.7)$ & $81.7(7.4) \dagger$ & $83.0(8.1)$ & $84.4(7.9)$ & $85(7)$ \\
\hline MMSE score, mean (SD) & $14.5(6.0)$ & $7.6(7.1) \dagger$ & & & $11(9)$ \\
\hline Symptoms & Dementia $^{3}$ & Dementia $^{1}$ & Dementia $^{1}$ & Dementia $^{3}$ & Dementia $^{2}$ \\
\hline Delusion & 26 & 9 & 15 & 24 & 16 \\
\hline Hallucination & 12 & 3 & 8 & 14 & 5 \\
\hline Agitation/aggression & 32 & 21 & 31 & 27 & 48 \\
\hline Depression & 20 & 9 & 20 & 22 & 20 \\
\hline Anxiety & 20 & 17 & 21 & 22 & 22 \\
\hline Euphoria & 5 & 4 & 7 & 6 & 7 \\
\hline Apathy & 26 & 19 & 34 & 29 & 23 \\
\hline Disinhibition & 17 & 13 & 20 & 21 & 18 \\
\hline Irritability & 35 & 28 & 34 & 29 & 31 \\
\hline $\mathrm{Ab}$ motor behaviour & 24 & 23 & 29 & 21 & 39 \\
\hline Night time behaviour & 14 & 6 & 12 & & \\
\hline Eating change & 13 & 14 & 24 & & \\
\hline \multirow[t]{2}{*}{ At least one CS-NPS* } & 70 & 68 & 81 & 72 & 84 \\
\hline & $\mathrm{NPI}>3$ & $\mathrm{NPI}>3$ & $\mathrm{NPI}>3$ & $\mathrm{NPI}>3$ & $\mathrm{NPI}>3$ \\
\hline
\end{tabular}

Course: The resolution rates for depression in the four studies reporting the course of NPS in nursing home patients were extremely divergent, ranging from $30 \%$ to $100 \%$ depending on the cohort, the severity of the dementia, and the time interval between the assessments, making a summary of the results difficult (35, $36,39,40)$. The resolution rates of anxiety were slightly more consistent, ranging from $33 \%$ to $75 \%$.

\section{Agitation}

Prevalence: The most prevalent NPS in the agitation sub-syndrome was irritability ( $28 \%$ to $35 \%$; median $31 \%$ ), followed by agitation/aggression (20\% to $48 \%$; median $27 \%$ ), aberrant motor behaviour $(20 \%$ to $39 \%$; median $24 \%$ ), and disinhibition (13\% to $21 \%$; median $18 \%)$.

Course: One study reported that approximately half of the patients with symptoms of agitation at inclusion were symptom-free after one year (39). As the time interval between the assessments decreased, the resolution rates for symptoms of agitation/aggression decreased as well, being approximately $35 \%$ in a study with assessments every fourth month (36).

\section{Apathy}

Prevalence: Six of the seven studies reported prevalence rates for apathy, which is a frequent symptom in persons with dementia, ranging from $19 \%$ to $34 \%$ and a median of $26 \%$.

Course: In the largest Norwegian nursing home study, there was a resolution rate for apathy of $47 \%$ over 1 year (40), while studies with assessments of apathy every fourth or sixth month reported a resolution rate of $30 \%$ to $47 \%$ and $45 \%$ to $64 \%$, respectively $(35,36)$.

\section{DISCUSSION}

In this review, we have described the prevalence and the course of neuropsychiatric symptoms (NPS) in patients with dementia, based on population-based studies, studies of outpatients, and studies of patients in long-term care. We found a high prevalence rate of NPS in patients with dementia; $56 \%$ to $88 \%$ of patients in population-based studies had at least one NPS (NPI $>0$ ) and $74 \%$ to $95 \%$ of outpatients had at least one NPS (NPI $>0$ ), while $68 \%$ to $84 \%$ of nursing home patients had at least one clinically significant NPS (NPI > 3). Overall, it has been estimated that up to $90 \%$ of patients with dementia will experience at least one clinically significant NPS through the course of the disease (41). The NPS with the highest prevalence rates at all three levels of care was apathy, while irritability, agitation/aggression, depression, and anxiety were slightly less frequent than apathy. Delusion, hallucination, disinhibition, aberrant motor behavior, and euphoria were the least frequent NPS in patients, independent of the level of care received by the patients who were recruited to the study. Delusions were considerably more frequent than hallucinations.

Although we have reviewed several studies and summarized the prevalence rates in them as medians and ranges, there are differences between individual studies with the same inclusion criteria. Further, comparison of prevalence rates between different levels of care is difficult. Nevertheless there are some trends. Patients in nursing homes have higher prevalence rates of all NPS, except for apathy, than patients in population-based cohorts. One explanation for this could be 
due to better treatment of apathy in nursing homes. The differences in severity of dementia between different levels of care may also explain differences in NPS prevalence rates between the cohorts, as there are increasing prevalence rates of NPS with increased severity of the dementia (34). Nevertheless, a recent review focusing on depression in dementia concluded that the prevalence rates of depression did not change across different stages of dementia (42). For psychotic symptoms, the prevalence rates of the patient's symptoms increase during the first three years of the disease, but later they don't change (43).

Studies from nursing homes in Norway generally report higher prevalence rates of psychotic symptoms than studies from nursing homes in other European countries. There are several possible explanations for this: 1) there are differences between the prevalence rates of psychosis in Norway and the rest of Europe; 2) the concept of delusion and hallucination is interpreted differently in the Norwegian version of the NPI compared to other versions of the NPI; and 3) the treatment of psychosis is less effective in Norway, resulting in higher prevalence rates. When looking at the prescription rates of antipsychotics in Norway and in the Netherlands, they are comparable $(33,35,36,44)$. On the other hand environmental aspects and how nursing homes are organized in the two countries differ, which may explain the differences in prevalence rates of psychotic symptoms. Also, patients in Dutch nursing homes have more severe dementia compared to patients in Norwegian nursing homes $(33,35,36,44)$.

The studies included in our review have different inclusion criteria. Ten studies have included patients independently of etiology of dementia diagnosis, and nine studies have included only those patients with a diagnosis of Alzheimer's disease. Generally, studies including only patients with Alzheimer's disease report higher prevalence rates of depression, anxiety, and apathy than studies that include patients independently of etiological dementia diagnosis. Psychotic symptoms seem to be less prevalent in patients with Alzheimer's disease than in patients with other etiologies of dementia. Previous studies have shown that as many as 50 to $80 \%$ of patients with Lewy Body dementia (LBD) or Parkinson's disease with dementia have visual hallucinations $(45,46)$. Disinhibition is also frequent in LBD, found in $65 \%$ of the patients (47). Depression, emotional lability and apathy is common in vascular dementia (VaD), especially depression, while psychosis is less prevalent in $\mathrm{VaD}$ than in other types of dementia (48). Depression and anxiety are found to be equally common in $\mathrm{VaD}$ as in $\mathrm{AD}$ (49). In patients with frontotemporal dementia (FTD), NPS such as apathy, disinhibition, irritability and aberrant social behaviour dominate their dementia while psychotic symptoms are very rare in patients with FTD (47). The differences in the prevalence of NPS in different types of dementia may be explained by underlying biological mechanisms. Low levels of serotonin in the CNS are known to be associated with depression or anxiety. Studies with functional neuroimaging demonstrate serotonergic dysfunction both in patients with $\mathrm{AD}$ and FTD, but the location of the serotonergic dysfunction in the brain varies between studies (50). In patients with Parkinson's disease and LBD, psychosis is thought to be a result from overstimulation of dopaminerigic receptors as well as an imbalance of serotonin and acetylcholine (51).

The presented review has some limitations. We have included only studies where the NPS is assessed by the NPI, which limits the number of included studies. The majority of the studies included in our review were from settings in North America and Europe, which is a paradox, as the majority of patients with dementia are living in countries in other parts of the world. There is a trend that studies from Asian countries report lower prevalence rates for symptoms of apathy and affective symptoms than studies from other countries $(21,23)$. There are differences in the criteria of a presenting NPS, which contributes to differences in the prevalence rates between the studies. It may also preclude the possibility of following the disease trajectory, in terms of prevalence rates, in patients with dementia in population-based samples through outpatients with dementia to patients with dementia in nursing homes.

What kinds of studies are needed in order to further increase our understanding of NPS in patients with dementia? More knowledge on the course of NPS is needed, and large, longitudinal cohort studies following patients with dementia from the beginning of their dementia disease until end-stage dementia should be planned. As most previous studies are on patients with Alzheimer's disease, future studies should be large enough to allow analyses of subgroups of dementia diagnoses as vascular dementia, Parkinson's disease with dementia, Lewy Body dementia, and frontotemporal dementia. The prevalence and course of NPS are influenced by the treatment given to the patients, and data on pharmacological treatment should be collected to allow for adjustments in the statistical analyses.

\section{CONCLUSION}

Neuropsychiatric symptoms (NPS) are prevalent in patients with dementia, and the prevalence rates increases with increasing severity of the dementia. There is also evidence that the prevalence rates of NPS are higher in nursing-home populations than in population-based samples. The most prevalent NPS are apathy, irritability, agitation/aggression, depression, and anxiety. Although NPS are prevalent, the patient's individual symptoms show a fluctuating course. Policy-makers and clinicians should be aware of the high prevalence rates of NPS and the fluctuating course of individual symptoms to better plan for further treatment and care of the elderly patients with dementia. 


\section{REFERENCES}

1. Ulstein I, Wyller TB, Engedal K. High score on the Relative Stress Scale, a marker of possible psychiatric disorder in family carers of patients with dementia. Int J Geriatr Psychiatry 2007; 22 (3): 195-202.

2. Black W, Almeida OP. A systematic review of the association between the Behavioral and Psychological Symptoms of Dementia and burden of care. Int Psychogeriatr 2004; 16 (3): 295-315.

3. Banerjee S, Samsi K, Petrie CD, Alvir J, Treglia M, Schwam EM, et al. What do we know about quality of life in dementia? A review of the emerging evidence on the predictive and explanatory value of disease specific measures of health related quality of life in people with dementia. Int J Geriatr Psychiatry 2009; 24 (1): $15-24$.

4. Banerjee S, Smith SC, Lamping DL, Harwood RH, Foley B, Smith P, et al. Quality of life in dementia: more than just cognition. An analysis of associations with quality of life in dementia. $J$ Neurol Neurosurg Psychiatry 2006; 77 (2): 146-8.

5. Ballard C, Corbett A. Management of neuropsychiatric symptoms in people with dementia. CNS Drugs 2010; 24 (9): 729-39.

6. Cummings JL, Mega M, Gray K, Rosenberg-Thompson S, Carusi DA, Gornbein J. The Neuropsychiatric Inventory: comprehensive assessment of psychopathology in dementia. Neurology 1994; 44 (12): 2308-14.

7. Cummings JL. The Neuropsychiatric Inventory: assessing psychopathology in dementia patients. Neurology 1997; 48 (5 Suppl 6): S10-S16.

8. Steinberg M, Tschanz JT, Corcoran C, Steffens DC, Norton MC, Lyketsos CG, et al. The persistence of neuropsychiatric symptoms in dementia: the Cache County Study. Int J Geriatr Psychiatry 2004; 19 (1): 19-26.

9. Aalten P, de Vugt ME, Lousberg R, Korten E, Jaspers N, Senden B, et al. Behavioral problems in dementia: a factor analysis of the neuropsychiatric inventory. Dement Geriatr Cogn Disord 2003; 15 (2): 99-105.

10. Selbaek G, Engedal K. Stability of the factor structure of the Neuropsychiatric Inventory in a 31-month follow-up study of a large sample of nursing-home patients with dementia. Int Psychogeriatr 2011; 24: 1-12.

11. Aarsland D, Bronnick K, Ehrt U, De Deyn PP, Tekin S, Emre M, et al. Neuropsychiatric symptoms in patients with Parkinson's disease and dementia: frequency, profile and associated care giver stress. J Neurol Neurosurg Psychiatry 2007; 78 (1): 36-42.

12. Lyketsos CG, Steinberg M, Tschanz JT, Norton MC, Steffens DC, Breitner JC. Mental and behavioral disturbances in dementia: findings from the Cache County Study on Memory in Aging. Am J Psychiatry 2000; 157 (5): 708-14.

13. Ikeda M, Fukuhara R, Shigenobu K, Hokoishi K, Maki N, Nebu A, et al. Dementia associated mental and behavioural disturbances in elderly people in the community: findings from the first Nakayama study. $J$ Neurol Neurosurg Psychiatry 2004; 75 (1): 146-8.

14. Tatsch MF, Bottino CM, Azevedo D, Hototian SR, Moscoso MA, Folquitto JC, et al. Neuropsychiatric symptoms in Alzheimer disease and cognitively impaired, nondemented elderly from a community-based sample in Brazil: prevalence and relationship with dementia severity. Am J Geriatr Psychiatry 2006; 14 (5): 438-45.

15. Lyketsos CG, Lopez O, Jones B, Fitzpatrick AL, Breitner J, DeKosky S. Prevalence of neuropsychiatric symptoms in dementia and mild cognitive impairment: results from the cardiovascular health study. JAMA 2002; 288 (12): 1475-83.

16. Steinberg M, Shao H, Zandi P, Lyketsos CG, Welsh-Bohmer KA, Norton MC, et al. Point and 5-year period prevalence of neuropsychiatric symptoms in dementia: the Cache County Study. Int J Geriatr Psychiatry 2008; 23 (2): 170-7.

17. Garcia-Alberca JM, Lara JP, Berthier ML, Cruz B, Barbancho MA, Green C, et al. Can impairment in memory, language and executive functions predict neuropsychiatric symptoms in Alzheimer's disease (AD)? Findings from a cross-sectional study. Arch Gerontol Geriatr 2011; 52 (3): 264-9.

18. Aalten P, Verhey FR, Boziki M, Bullock R, Byrne EJ, Camus V, et al. Neuropsychiatric syndromes in dementia. Results from the European Alzheimer Disease Consortium: part I. Dement Geriatr Cogn Disord 2007; 24 (6): 457-63.

19. Toyota Y, Ikeda M, Shinagawa S, Matsumoto T, Matsumoto N, Hokoishi K, et al. Comparison of behavioral and psychological symptoms in early-onset and late-onset Alzheimer's disease. Int J Geriatr Psychiatry 2007; 22 (9): 896-901.

20. Peters KR, Rockwood K, Black SE, Bouchard R, Gauthier S, Hogan D, et al. Characterizing neuropsychiatric symptoms in subjects referred to dementia clinics. Neurology 2006; 66 (4): 523-8.

21. Senanarong V, Poungvarin N, Jamjumras P, Sriboonroung A, Danchaivijit C, Udomphanthuruk S, et al. Neuropsychiatric symptoms, functional impairment and executive ability in Thai patients with Alzheimer's disease. Int Psychogeriatr 2005; 17 (1): 81-90.

22. Piccininni M, Di CA, Baldereschi M, Zaccara G, Inzitari D. Behavioral and psychological symptoms in Alzheimer's disease: frequency and relationship with duration and severity of the disease. Dement Geriatr Cogn Disord 2005; 19 (5-6): 276-81.

23. Fuh JL, Wang SJ, Cummings JL. Neuropsychiatric profiles in patients with Alzheimer's disease and vascular dementia. J Neurol Neurosurg Psychiatry 2005; 76 (10): 1337-41.

24. Mega MS, Cummings JL, Fiorello T, Gornbein J. The spectrum of behavioral changes in Alzheimer's disease. Neurology 1996; 46 (1): 130-5. 
25. Benoit M, Staccini P, Brocker P, Benhamidat T, Bertogliati C, Lechowski L, et al. [Behavioral and psychologic symptoms in Alzheimer's disease: results of the REAL.FR study]. Rev Med Interne 2003; 24 (Suppl 3): $319 \mathrm{~s}-24 \mathrm{~s}$.

26. Gonfrier S, Andrieu S, Renaud D, Vellas B, Robert PH. Course of neuropsychiatric symptoms during a 4-year follow up in the REAL-FR cohort. J Nutr Health Aging 2012; 16 (2): 134-7.

27. Devanand DP, Jacobs DM, Tang MX, Castillo-Castaneda C, Sano M, Marder K, et al. The course of psychopathologic features in mild to moderate Alzheimer disease. Arch Gen Psychiatry 1997; 54 (3): 257-63.

28. Hope T, Keene J, Fairburn CG, Jacoby R, McShane R. Natural history of behavioural changes and psychiatric symptoms in Alzheimer's disease. Br J Psychiatry 1999; 174: 39-44.

29. Haupt M, Kurz A, Janner M. A 2-year follow-up of behavioural and psychological symptoms in Alzheimer's disease. Dement Geriatr Cogn Disord 2000; 11 (3): 147-52.

30. Eustace A, Coen R, Walsh C, Cunningham CJ, Walsh JB, Coakley D, et al. A longitudinal evaluation of behavioural and psychological symptoms of probable Alzheimer's disease. Int J Geriatr Psychiatry 2002; 17 (10): 968-73.

31. Aalten P, de Vugt ME, Jaspers N, Jolles J, Verhey FR. The course of neuropsychiatric symptoms in dementia. Part I: findings from the two-year longitudinal Maasbed study. Int J Geriatr Psychiatry 2005; 20 (6): 523-30.

32. Benoit M, Robert PH, Staccini P, Brocker P, Guerin O, Lechowski L, et al. One-year longitudinal evaluation of neuropsychiatric symptoms in Alzheimer's disease. The REAL.FR Study. J Nutr Health Aging $2005 ; 9$ (2): 95-9.

33. Zuidema SU, Derksen E, Verhey FR, Koopmans RT. Prevalence of neuropsychiatric symptoms in a large sample of Dutch nursing home patients with dementia. Int J Geriatr Psychiatry 2007; 22 (7): 632-8.

34. Selbaek G, Kirkevold O, Engedal K. The prevalence of psychiatric symptoms and behavioural disturbances and the use of psychotropic drugs in Norwegian nursing homes. Int J Geriatr Psychiatry 2007; 222 (9): 843-9.

35. Wetzels RB, Zuidema SU, de Jonghe JF, Verhey FR, Koopmans RT. Course of neuropsychiatric symptoms in residents with dementia in nursing homes over 2-year period. Am J Geriatr Psychiatry 2010; 18 (12): 105465 .

36. Bergh S, Engedal K, Roen I, Selbaek G. The course of neuropsychiatric symptoms in patients with dementia in Norwegian nursing homes. Int Psychogeriatr 2011; 23 (8): 1231-9.

37. Margallo-Lana M, Swann A, O'Brien J, Fairbairn A, Reichelt K, Potkins D, et al. Prevalence and pharmacological management of behavioural and psychological symptoms amongst dementia sufferers living in care environments. Int J Geriatr Psychiatry 2001; 16 (1): 39-44.

38. Wetzels R, Zuidema S, Jansen I, Verhey F, Koopmans R. Course of neuropsychiatric symptoms in residents with dementia in long-term care institutions: a systematic review. Int Psychogeriatr 2010; 22 (7): 1040-53.

39. Ballard C, Margallo-Lana M, Fossey J, Reichelt K, Myint P, Potkins D, et al. A 1-year follow-up study of behavioral and psychological symptoms in dementia among people in care environments. J Clin Psychiatry 2001; 62 (8): 631-6.

40. Selbaek G, Kirkevold O, Engedal K. The course of psychiatric and behavioral symptoms and the use of psychotropic medication in patients with dementia in Norwegian nursing homes - a 12-month follow-up study. Am J Geriatr Psychiatry 2008; 16 (7): 528-36.

41. Robert PH, Verhey FR, Byrne EJ, Hurt C, De Deyn PP, Nobili F, et al. Grouping for behavioral and psychological symptoms in dementia: clinical and biological aspects. Consensus paper of the European Alzheimer disease consortium. Eur Psychiatry 2005; 20 (7): 490-6.

42. Verkaik R, Nuyen J, Schellevis F, Francke A. The relationship between severity of Alzheimer's disease and prevalence of comorbid depressive symptoms and depression: a systematic review. Int J Geriatr Psychiatry 2007; 22 (11): 1063-86.

43. Ropacki SA, Jeste DV. Epidemiology of and risk factors for psychosis of Alzheimer's disease: a review of 55 studies published from 1990 to 2003. Am J Psychiatry 2005; 162 (11): 2022-30.

44. Selbaek G, Kirkevold O, Engedal K. Psychiatric and behavioural symptoms and the use of psychotropic medication in Special Care Units and Regular Units in Norwegian nursing homes. Scand J Caring Sci 2008; 22 (4): 568-73.

45. Harding AJ, Broe GA, Halliday GM. Visual hallucinations in Lewy body disease relate to Lewy bodies in the temporal lobe. Brain 2002; 125 (Pt 2): 391-403.

46. Gold G. Dementia with Lewy bodies: clinical diagnosis and therapeutic approach. Front Neurol Neurosci 2009; 24: 107-13.

47. Engelborghs S, Maertens K, Nagels G, Vloeberghs E, Marien P, Symons A, et al. Neuropsychiatric symptoms of dementia: cross-sectional analysis from a prospective, longitudinal Belgian study. Int J Geriatr Psychiatry 2005; 20 (11): 1028-37.

48. O'Brien J. Behavioral symptoms in vascular cognitive impairment and vascular dementia. Int Psychogeriatr 2003; 15 (Suppl 1): 133-8.

49. Ballard C, Neill D, O'Brien J, McKeith IG, Ince P, Perry R. Anxiety, depression and psychosis in vascular dementia: prevalence and associations. J Affect Disord 2000; 59 (2): 97-106.

50. Salmon E. A review of the literature on neuroimaging of serotoninergic function in Alzheimer's disease and related disorders. J Neural Transm 2007; 114 (9): 1179-85.

51. Fenelon G. Psychosis in Parkinson's disease: phenomenology, frequency, risk factors, and current understanding of pathophysiologic mechanisms. CNS Spectr 2008; 13 (3 Suppl 4): 18-25. 